\title{
Comparative prospective randomized study of minimally invasive transpiriformis approach versus conventional posterolateral approach in total hip arthroplasty as measured by biology markers
}

\author{
Cong Xiao ${ }^{1}$. Zhixiang Gao ${ }^{1}$ Shaoyun Zhang ${ }^{1}$ - Nengji Long ${ }^{1} \cdot$ Kai Yao $^{1} \cdot$ Peng Cai ${ }^{1} \cdot$ Fenglai He $^{1} \cdot$ Lijuan Liu $^{1}$. \\ Yishan Jiang ${ }^{1}$ (I)
}

Received: 20 April 2021 / Accepted: 13 May 2021 / Published online: 27 May 2021

(c) The Author(s) 2021

\begin{abstract}
Background Minimally invasive surgery is becoming increasingly common, but evidence of the advantages of the minimally invasive transpiriformis approach in total hip arthroplasty is limited. Therefore, our single-centre randomized controlled trial evaluated the benefits of this approach versus the posterolateral approach.

Methods Forty-nine patients undergoing the minimally invasive transpiriformis approach and 57 patients undergoing the posterolateral approach total hip arthroplasty were analyzed. The operative time, length of hospital stay, incision length, and peri-operative data related to the surgery were recorded. In both groups, serum CRP, IL-6, HGb, Hct, MB, CK-MB, and CK levels, Harris hip scores, and VAS scores were recorded.

Results Patients who underwent the minimally invasive transpiriformis approach had a smaller surgical incision $(9.10 \pm 0.94$ vs. $15.56 \pm 1.20 \mathrm{~cm}, \mathrm{P}=0.00)$ and shorter hospital stay $(6.20 \pm 1.54$ vs. $12.26 \pm 2.97$ days, $\mathrm{P}=0.00)$ than those who underwent the posterolateral approach. Serum levels of CRP, IL-6, MB, CK-MB, and CK were also lower. According to the Harris hip score, the minimally invasive transpiriformis group showed significant improvement at one week and one month after surgery.

Conclusion Compared to the posterolateral approach, the minimally invasive transpiriformis approach for total hip arthroplasty provided rapid functional recovery, elicited a significantly reduced post-operative inflammatory response, and caused less muscle damage.
\end{abstract}

Keywords Total hip arthroplasty $\cdot$ Piriformis $\cdot$ Posterolateral $\cdot$ Posterolateral approach $\cdot$ Short external rotators

Cong Xiao and Zhixiang Gao contributed equally to this work.

Yishan Jiang

jiangysh@126.com

Cong Xiao

syygekxc@126.com

Zhixiang Gao

jwkgzx@126.com

Shaoyun Zhang

zhangsyhm2068@163.com

Nengji Long

925675340@qq.com

Kai Yao

2319187373@qq.com
Peng Cai

102180054@qq.com

Fenglai He

22833532@qq.com

Lijuan Liu

649465221@qq.com

1 Department of Orthopedics, The Third Hospital

of Mianyang, Sichuan Mental Health Center, No. 190 The East Jiannan Road, Mianyang 621000, China 


\section{Introduction}

Since the early 1960s [1], when the father of modern hip replacement, John Charnley, performed joint replacement surgery, artificial joint replacement has evolved and is now a mature, standard orthopaedic treatment technique that can effectively restore joint function and improve the quality of life of patients $[2,3]$. However, the disadvantages of traditional total hip arthroplasty (THA) with the posterolateral approach (PLA), such as greater trauma, more blood loss, significant pain, and a high dislocation rate [4], have led to increasing concerns regarding how to minimize the intra-operative damage to the soft tissues of the hip, which poses a new challenge to orthopaedic surgeons. Minimally invasive THA has grown in popularity worldwide during the last decade due to its smaller skin incisions, reduced muscle damage, shorter post-operative hospital stays, and faster functional recovery $[5,6]$. Currently, the surgical approaches for minimally invasive THA include anterior, anterolateral [7, 8], lateral [9], posterolateral, and posterolateral approaches [10], each of which has its own advantages and disadvantages. Although anterior and anterolateral surgery can be achieved through the intermuscular plane, which preserves the posterior joint capsule and reduces the risk of post-operative joint dislocation, there are difficulties in terms of femoral exposure or even fracture, the high error rate of prosthesis implantation, risk of vascular nerve injury, steep learning curve, and need for custom-made instruments $[11,12]$.

In 2008, Penenberg et al. [13]. proposed percutaneously assisted total hip arthroplasty (PATH) without disruption of the external rotator muscle group; however, customized instrumentation is required to assist in the implantation of the prosthetic acetabular cup. Therefore, in 2012, Roger et al. [14] suggested performing THA through the transpiriformis approach based on Penenberg et al. In 135 patients, the average surgical incision length was $9 \mathrm{~cm}$, with no dislocation, no sciatic nerve palsy, no wound complications, a low transfusion rate ( $8 \%$ ), an average acetabular cup abduction angle of $41^{\circ}\left(\right.$ range $\left.21-49^{\circ}\right)$, an average anteversion angle of $21^{\circ}\left(15-27^{\circ}\right)$, femoral prosthesis with more than $2^{\circ}$ of varus deviation in $4 \%$, and more than $2^{\circ}$ of valgus deviation in $2 \%$, with good clinical outcomes. However, the study was retrospective and lacked comparisons with other surgical approaches. Therefore, our goal was to determine whether this approach offers superior clinical results by a prospective randomized controlled trial.

The definition of a minimally invasive total hip is not limited to an incision of less than $10 \mathrm{~cm}$ but also little damage to soft tissues and muscles $[9,15]$. Studies have shown that elevated post-operative serum creatine kinase (CK) can reflect the degree of muscle damage and that elevated
C-reactive protein (CRP) can reflect the degree of inflammation, so the traumatic effects of surgery can be measured objectively using CK and markers of inflammation [16, 17]. To date, no relevant studies in the literature have reported changes in regard to muscle injury and inflammatory indexes in minimally invasive THA through the transpiriformis approach. We hypothesize that minimally invasive THA through the transpiriformis approach can reduce postoperative CK and CRP indexes and reduce pain in patients.

\section{Materials and methods}

This study is a prospective, randomized controlled trial approved by the ethics committee of the hospital and registered with the Chinese Clinical Trials Registry (ChiCTR2000029515). A total of 106 patients diagnosed with unilateral femoral neck fracture between December 2019 and May 2020 were recruited for this study, and all patients provided informed written consent (Fig. 1).

Inclusion criteria are as follows: unilateral primary or secondary hip osteoarthritis, femoral neck fracture, and body mass index $<30 \mathrm{~kg} / \mathrm{m}^{2}$. Exclusion criteria are as follows: hip ankylosis, hip flexion contracture, developmental dysplasia of the hip, previous history of hip surgery, bone cement prosthesis, neurological disorders, or musculoskeletal impairments that adversely affect gait or weight-bearing and refusal to participate in the study. Simple randomization was performed using a random number table randomization to assign patients to either the minimally invasive transpiriformis approach group or the posterolateral approach group. During the inclusion period (December 2019 and May 2020), there were 131 primary total hip arthroplasties performed at our hospital. Nine patients declined to participate, 12 patients had a body mass index (BMI) over $30 \mathrm{~kg} / \mathrm{m}^{2}$, and two patients had developmental dysplasia of the hip. Thus, 108 patients were eligible for randomization. Forty-nine were randomly assigned to the minimally invasive transpiriformis approach, and 59 were randomly assigned to the posterolateral approach. The follow-up of all patients was three months. Zero patients were lost to the minimally invasive transpiriformis approach, and two patients were lost to the posterolateral approach group, which resulted in 49 patients in the minimally invasive transpiriformis approach and 57 patients in the posterolateral approach.

Baseline demographic data including sex, age, weight, height, body mass index (BMI), American Society of Anesthesiologists (ASA) grade, pre-operative myoglobin (MB), CK, CRP, interleukin 6 (IL-6), haemoglobin (HGb), and haematocrit (Hct) levels were recorded for all patients before surgery. The pre-operative general data of the patients in both groups are presented in Table 1, and the differences between the groups were not statistically significant. 
Table 1 Pre-operative characteristics of patients

\begin{tabular}{lllll}
\hline & $\begin{array}{l}\text { Minimally invasive } \\
\text { transpiriformis approach }(\mathrm{n}=49)\end{array}$ & $\begin{array}{l}\text { Posterolateral } \\
\text { approach }(\mathrm{n}=57)\end{array}$ & $\begin{array}{l}\text { Difference in means } \\
(95 \% \mathrm{CI})\end{array}$ & P value \\
\hline Age (years) & $71.06 \pm 10.87$ & $73.93 \pm 10.02$ & $2.03(-6.89-1.16)$ & 0.16 \\
Sex $(\mathrm{M} / \mathrm{F})$ & $16 / 33$ & $26 / 31$ & - & 0.23 \\
BMI $\left(\mathrm{kg} / \mathrm{m}^{2}\right)$ & $26.73 \pm 4.18$ & $26.39 \pm 4.64$ & $0.86(-1.37-2.05)$ & 0.69 \\
ASA grade & $2.01 \pm 0.12$ & $2.05 \pm 0.39$ & $0.06(-0.16-0.06)$ & 0.36 \\
Side (L/R) & $21 / 28$ & $24 / 33$ & - & 0.94 \\
CRP (mg/l) & $16.83 \pm 12.77$ & $17.70 \pm 14.40$ & $2.66(-6.15-4.41)$ & 0.74 \\
IL-6 (pg/ml) & $4.67 \pm 1.87$ & $4.84 \pm 1.22$ & $0.30(-0.77-0.42)$ & 0.56 \\
CK (U/L) & $79.25 \pm 13.01$ & $77.53 \pm 27.53$ & $4.29(-6.79-10.24)$ & 0.69 \\
CK-MB (U/L) & $8.41 \pm 5.68$ & $9.55 \pm 4.84$ & $1.02(-3.17-0.88)$ & 0.27 \\
MB (ng/ml) & $51.88 \pm 11.34$ & $53.89 \pm 7.40$ & $1.84(-5.65-1.64)$ & 0.28 \\
HGB (g/l) & $121.58 \pm 11.24$ & $117.32 \pm 17.45$ & $2.90(-1.49-10.02)$ & 0.15 \\
HCT (\%) & $37.15 \pm 3.50$ & $36.32 \pm 4.04$ & $0.74(-0.64-2.29)$ & 0.27 \\
\hline
\end{tabular}

We recorded the surgery time, skin incision length, surgery time, blood transfusion rate, and hospital stay. The changes in the levels of CRP, IL-6, HGb, Hct, MB, $\mathrm{CK}-\mathrm{MB}$, and $\mathrm{CK}$ on post-operative days one and three were recorded. Assessment of pain on post-operative days, zero, one, two and four was performed using the visual analog scale (VAS), with a score of 0 indicating no pain, 10 indicating severe pain, and 0 to 10 indicating varying degrees of pain. Additionally, the Harris hip score (HSS) was measured at one week, one month, and three months post-operatively.

\section{Surgical approaches}

\section{Minimally invasive transpiriformis approach}

An experienced orthopaedic surgeon carried out all operations. The patient is placed in the lateral position. Take the greater trochanter of the femur as the starting point along the direction of the femoral stem marked $\mathrm{AB}=4 \mathrm{~cm}$ and $\mathrm{BC}=5 \mathrm{~cm}$, respectively, and draw $\mathrm{BD}=3 \mathrm{~cm}$ perpendicular to $\mathrm{AC}$, with point $\mathrm{D}$ as the starting point extending proximally along the direction of CD for an average of $\mathrm{DE}=9 \mathrm{~cm}$ as the surgical incision (Fig. 2a). The skin and subcutaneous tissues were incised, the gluteus maximus fibers were bluntly separated along the gluteus, and the deep pyriform muscle was explored (Fig. 2b). Hoffman's pull hooks were placed superior and inferior to the piriformis muscle to protect the gluteus medius and the external rotators (internal obturator muscle and gemellus superior, respectively) (Fig. 3). The posterior joint capsule was exposed by cutting the stop of the pyriform muscle on the greater trochanter and scalloping the joint capsule to expose the femoral neck (Figs. 4 and 5).

Hip dislocation was achieved by flexion, internal rotation, and internal retraction, and femoral neck osteotomy was performed. Hoffman pulling hooks were placed at each of the anterior and inferior edges of the acetabulum to reveal the acetabulum (Fig. 6). The position of the desired acetabular prosthesis is $40^{\circ} \pm 10^{\circ}$ of abduction and $15^{\circ} \pm 10^{\circ}$ of anteversion [18] (Fig. 7). The femoral prosthesis was implanted according to preoperative template measurements and intra-operative assessment, and the hip was repositioned by external rotation. The stability of the hip was checked in flexion at $90^{\circ}$, adduction at $20^{\circ}$, and internal rotation at $50^{\circ}$. The wound was extensively irrigated with saline, the joint capsule was repaired, and the pyriform stop was reconstructed; this approach does not require a drainage tube (Fig. 8a-c). The skin was closed with intradermal sutures (Fig. 9).

\section{Posterolateral approach (PA)}

Patients were placed in the standard lateral position. A surgical incision of approximately $14-16 \mathrm{~cm}$ was made on the hip's posterolateral surface to incise the skin, subcutaneous tissue, gluteus maximus, external rotators, and posterior capsule. For hip joint dislocation, the femoral neck was osteotomized, and the acetabular and femoral prostheses were implanted in the same way as in the transpiriformis approach. The drainage tube was retained post-operatively until the flow was $<50 \mathrm{ml} /$ day.

\section{Statistical analysis}

Comparison of continuous variables between groups was performed by paired t-test and unpaired t-test when necessary; Fisher's exact t-test or $\chi^{2}$ test was applied to compare categorical variables. Spearman's correlation analysis analyzed the correlation between operative time and $\mathrm{CK}$, with $P<0.05$ considered significant. 
Fig. 1 Patient flow chart

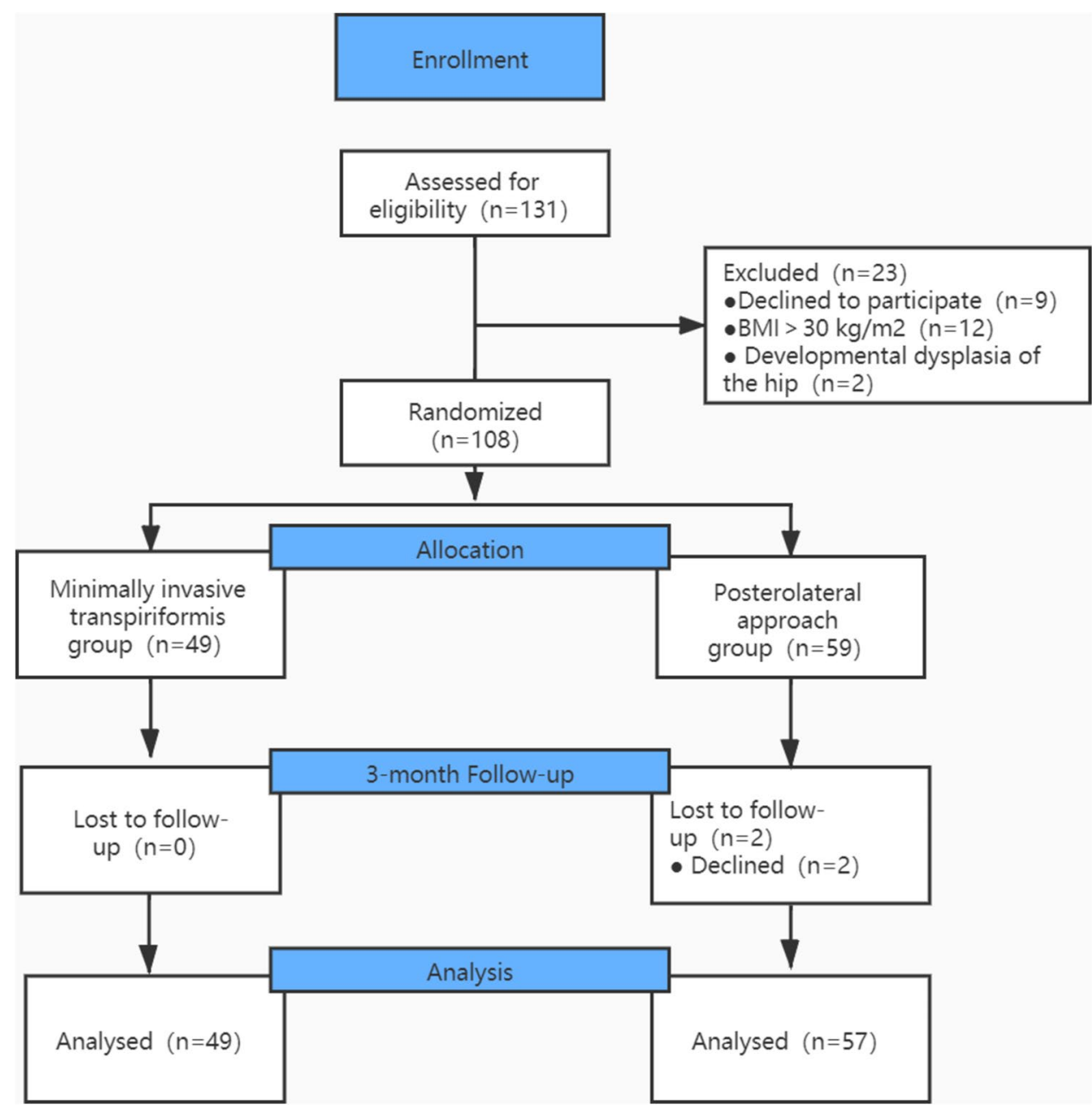

\section{Results}

The minimally invasive transpiriformis group consisted of 49 patients (16 males and 33 females) with a mean age of $71.06 \pm 10.87$ years; the posterolateral group consisted of 57 patients (26 males and 31 females) with a mean age of $73.93 \pm 10.02$ years. In the minimally invasive transpiriformis group, the mean operative time was $84.47 \pm 19.37 \mathrm{~min}$, and the mean incision length was $9.10 \pm 0.94 \mathrm{~cm}$; in the posterolateral group, the mean
Fig. 2 a The patient is positioned laterally on the operating table, and the incision is approximately $9 \mathrm{~cm}$ DE. b The gluteus maximus muscle is split in the direction of the gluteus maximus fibers to reveal the short external rotators such as the musculus piriformis. $\mathrm{P}$, "piriformis"; SG, "superior gemellus"; OI, "obturator internus"; IG, "inferior gemellus"; $\mathrm{SN}$, "sciatic nerve"

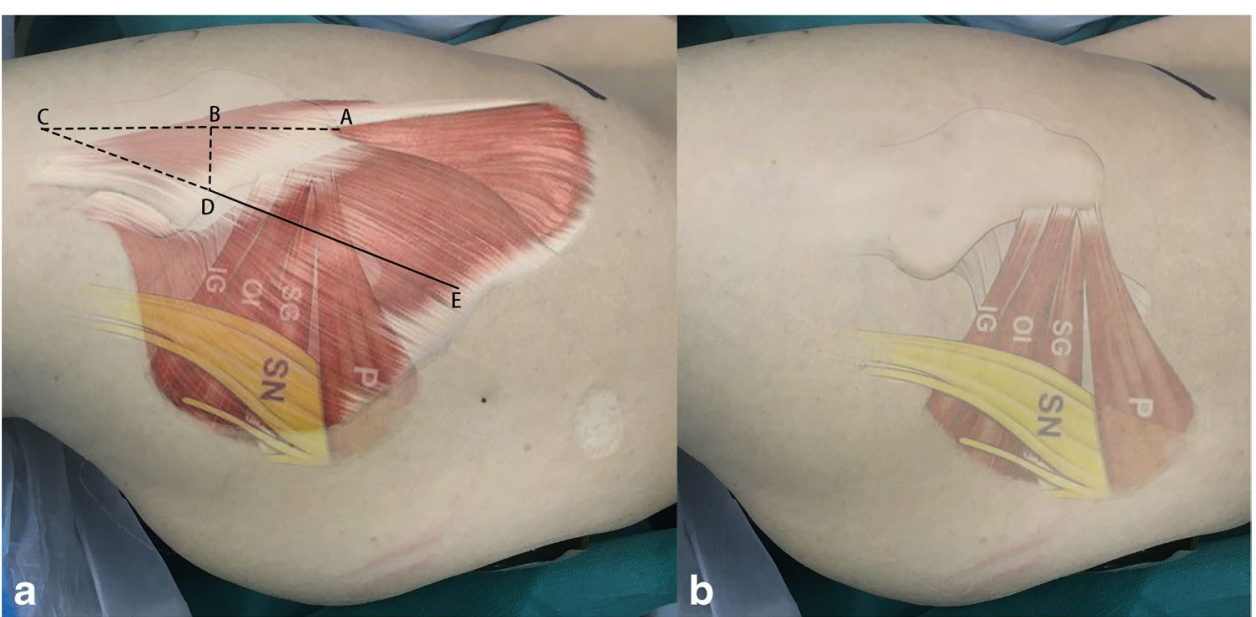




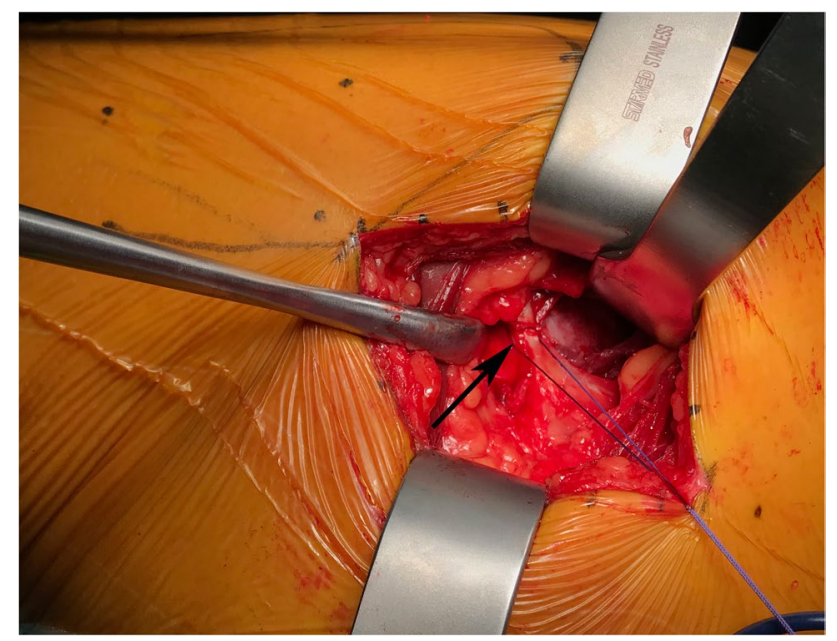

Fig. 3 Confirmation and suturing of the piriformis tendon, the release of the tendon at the greater trochanter. The black arrow is the piriformis tendon

operative time was $105.44 \pm 10.50 \mathrm{~min}$, and the mean incision length was $15.56 \pm 1.20 \mathrm{~cm}$. The operative time and incision length were lower in the minimally invasive transpiriformis group $(\mathrm{P}=0.00)$ (Table 2).

Compared with the pre-operative $\mathrm{HGb}$ and HCT, the minimally invasive transpiriformis and posterolateral groups decreased gradually on the first and third post-operative days, and the posterolateral group showed a more significant decrease in HGb and HCT after surgery $(\mathrm{P}=0.00)$ (Table 2). HGb and HCT loss were calculated by the difference between pre-operative $\mathrm{HGb}$ and HCT and the first and third post-operative days. The minimally invasive transpiriformis group showed a decrease in HGb $(18.80 \pm 9.15 \mathrm{~g} / \mathrm{l})$ and HCT $(19.12 \pm 9.63 \%)$ on the first post-operative

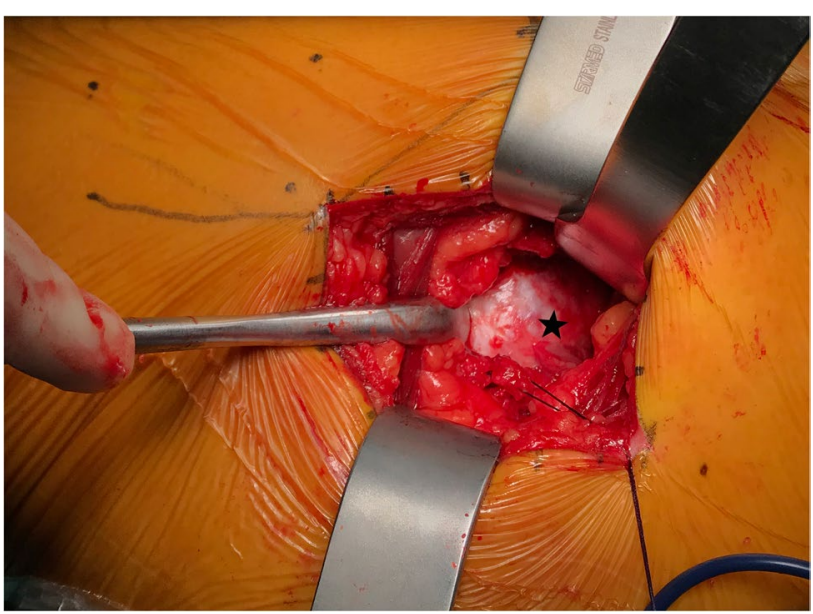

Fig. 4 The joint capsule is visible after dissection of the piriformis tendon. The black pentagon is the posterior joint capsule

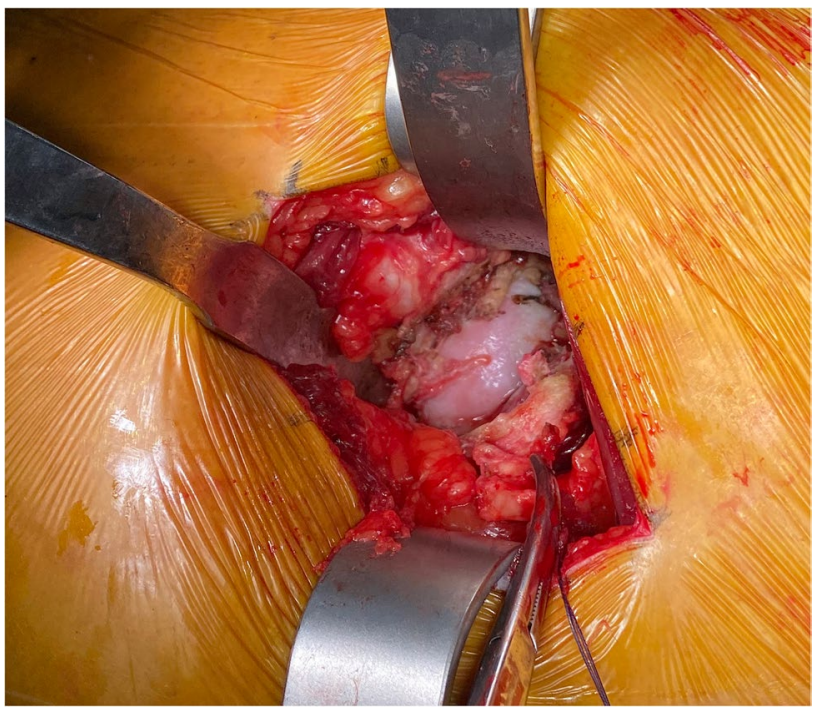

Fig. 5 Two Hoffman hooks were placed to expose the femoral neck

day and a decrease in HGb $(23.44 \pm 10.40 \mathrm{~g} / \mathrm{l})$ and HCT $(24.49 \pm 9.54 \%)$ on the third post-operative day. In the posterolateral group, HGb decreased by $20.44 \pm 10.76 \mathrm{~g} / \mathrm{l}$ and HCT decreased by $21.79 \pm 8.19 \%$ on the first post-operative day, and HGb decreased by $24.05 \pm 9.77 \mathrm{~g} / 1$ and HCT decreased by $26.04 \pm 1.35 \%$ on the third post-operative day. However, there was no significant difference between the minimally invasive transpiriformis and posterolateral groups in comparing $\mathrm{HGb}$ and $\mathrm{HCT}$ decline in the first and third days after surgery $(\mathrm{P}>0.05)$ (Table 2$)$.

Serum CRP levels gradually increased on the first and third post-operative days, reaching a maximum on the third post-operative day at our monitoring time point, reaching $97.21 \pm 39.27 \mathrm{mg} / \mathrm{l}$ in the minimally invasive transpiriformis

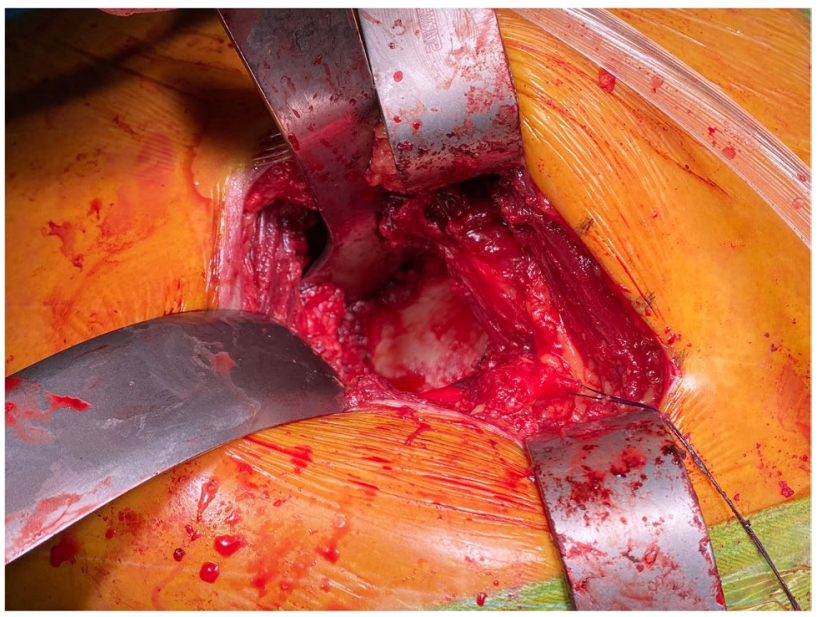

Fig. 6 Two Hoffman hooks and two retractors were placed to expose the acetabulum 


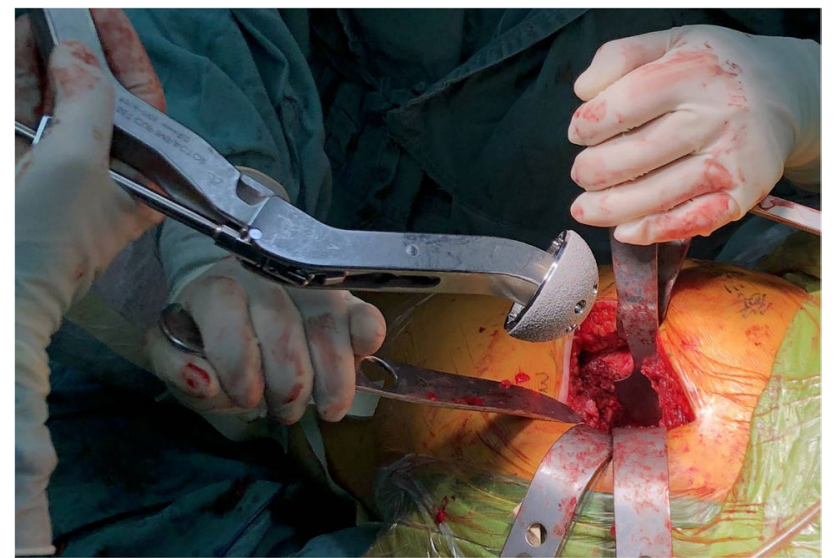

Fig. 7 Acetabulum polished by eccentric file and implanted with prosthesis

group and $113.29 \pm 4.98 \mathrm{mg} / \mathrm{l}$ in the posterolateral group (Table 3). All patients had higher post-operative serum CRP levels in the posterolateral group than in the minimally invasive transpiriformis group; the differences were statistically significant on the first $(\mathrm{P}=0.00)$ and third $(\mathrm{P}=0.00)$ post-operative days (Table 3 ). Compared to the minimally invasive transpiriformis group, IL-6 levels were significantly higher in the posterolateral group on the first and third postoperative days, with a statistically significant difference $(\mathrm{P}=0.00)$.

Minimally invasive transpiriformis and posterolateral group serum CK $(476.67 \pm 87.44$ vs. $613.77 \pm 25.35)$ U/L, CK-MB (32.42 \pm 21.85 vs. $38.41 \pm 2.02) \mathrm{U} / \mathrm{L}, \mathrm{MB}$ $(511.11 \pm 189.40 \mathrm{VS} 801.09 \pm 22.47) \mathrm{ng} / \mathrm{ml}$ were elevated on the first post-operative day but showed a decrease on the third post-operative day (CK $(370.23 \pm 249.37 \mathrm{VS}$ $504.62 \pm 21.88) \mathrm{U} / \mathrm{L}, \mathrm{CK}-\mathrm{MB}(8.28 \pm 5.86$ VS $19.20 \pm 15.13)$ $\mathrm{U} / \mathrm{L}, \mathrm{MB}(148.32 \pm 91.98 \mathrm{VS} 182.14 \pm 12.51) \mathrm{ng} / \mathrm{ml})$. Overall, the posterolateral group showed higher serum CK, CK-MB, and MB levels than the minimally invasive transpiriformis group $(\mathrm{P}=0.00)$ (Table 3$)$. We next attempted to determine the relationship between surgery time and CK by correlation analysis. Figure 10a and b shows a low correlation between surgery duration and changes in CK levels regardless of whether the patients were in the minimally invasive transpiriformis group or the posterolateral group.

Figure 11 shows that the VAS scores of patients in the posterolateral group were higher than those in the minimally invasive transpiriformis group on post-operative days zero to four, with a statistically significant difference between the two groups observed in the first three days $(P=0.00)$, but no statistically significant difference was noted on the fourth day $(\mathrm{P}>0.05)$.

Both groups showed significant improvement in the HSS from pre-operatively to one week, one month, and three months post-operatively. The minimally invasive transpiriformis group had a higher HSS at one week and one month than the posterolateral group $(\mathrm{P}=0.00)$. However, the score of minimally invasive transpiriformis group was only one point higher than that of the posterolateral group at three months post-operatively, and the difference between the two groups was not statistically significant (P>0.05) (Fig. 12).

\section{Discussion}

Minimally invasive total hip arthroplasty can reduce the damage to the soft tissues around the joint and protect joint stability and power, leading to earlier and better functional exercise tolerance and rapid recovery. Currently, the consensus on minimally invasive total hip arthroplasty is that the surgical incision length should be less than $10 \mathrm{~cm}[9,15]$. However, this definition is more controversial, and no further measurement of soft tissue damage has been made. Indicators of CK and inflammation best reflect the level of soft tissue damage during surgery. This is an accurate measure of minimal invasion during a surgical procedure.

$\mathrm{CK}$ is present in the cardiac muscle, brain, skeletal muscle, and other tissues. Although CK is considered a sensitive marker of myocardial injury, it is present in high

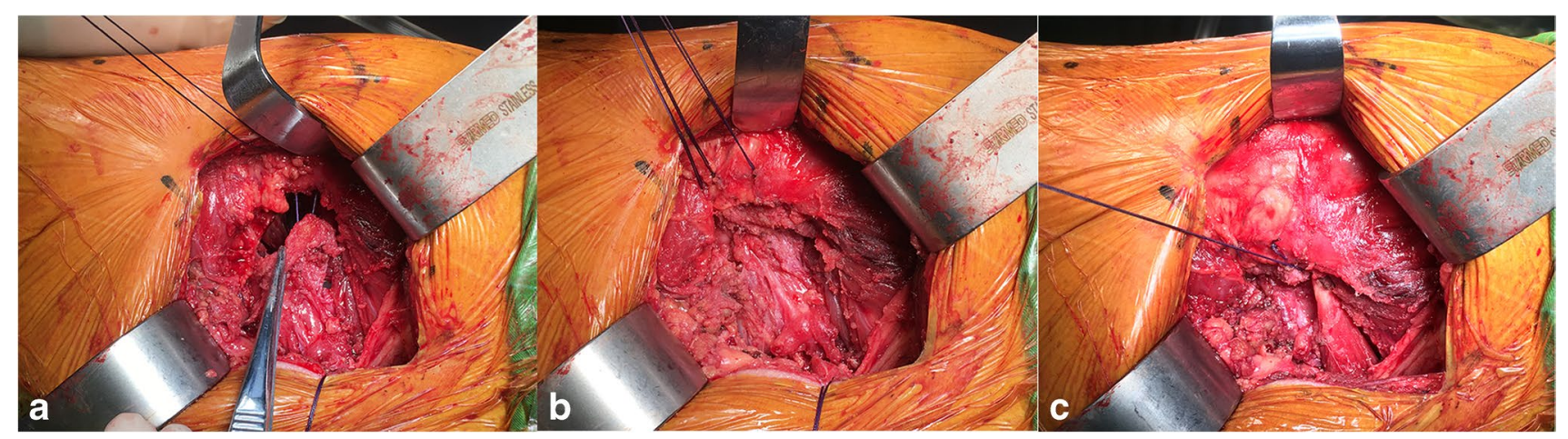

Fig. 8 The posterior joint capsule and piriformis tendon were repaired in turn at the greater trochanter 
Table 2 Peri-operative data of patients

\begin{tabular}{llll}
\hline & $\begin{array}{l}\text { Minimally invasive transpiri- } \\
\text { formis approach }(\mathrm{n}=49)\end{array}$ & $\begin{array}{l}\text { Posterolateral } \\
\text { approach }(\mathrm{n}=57)\end{array}$ & Difference in means(95\%CI) \\
\hline Length of hospital stay (days) & $6.20 \pm 1.54$ & $12.26 \pm 2.97$ & $0.47(-6.99-5.12)$ \\
$\quad$ Length of incision (cm) & $9.10 \pm 0.94$ & $15.56 \pm 1.20$ & $0.21(-6.87-6.03)$ \\
$\quad$ Operative time (min) & $84.47 \pm 19.37$ & $105.44 \pm 10.50$ & $2.97(-26.86-15.08)$ \\
HGB(g/l) & & & 0.00 \\
1st post-operative day & $98.76 \pm 10.38$ & $94.09 \pm 9.42$ & $1.92(0.86-8.48)$ \\
1st post-operative day decline rate & $18.80 \pm 9.15$ & $20.44 \pm 10.76$ & $1.96(-5.52-2.24)$ \\
3rd post-operative day & $92.54 \pm 8.89$ & $89.10 \pm 1.47$ & $1.19(1.07-5.81)$ \\
3rd post-operative day decline rate & $23.44 \pm 10.40$ & $24.05 \pm 9.77$ & $1.73(-6.10-0.77)$ \\
HCT(\%) & & & 0.00 \\
1st post-operative day & $30.07 \pm 3.06$ & $28.22 \pm 0.29$ & $0.41(1.04-2.66)$ \\
1st post-operative day decline rate & $19.12 \pm 9.63$ & $21.79 \pm 8.19$ & $1.96(-4.50-3.28)$ \\
3rd post-operative day & $27.83 \pm 2.41$ & $25.45 \pm 1.27$ & $0.37(1.65-3.10)$ \\
3rd post-operative day decline rate & $24.49 \pm 9.54$ & $26.04 \pm 1.35$ & $1.28(-4.09-0.98)$ \\
\hline
\end{tabular}

concentrations in skeletal muscle, where CK is a dimeric enzyme present in the sarcoplasm. The concentration of CK in the circulation is low in healthy individuals, and when muscle cell membranes are damaged, CK is released into the bloodstream. Therefore, $\mathrm{CK}$ is a preferable indicator for assessing muscle damage. Musil et al. [19] compared postoperative levels of $\mathrm{CK}$ in a prospective randomized study of patients undergoing the posterolateral approach versus those undergoing the minimally invasive anterolateral (MIS-AL) approach. Serum CK levels among patients undergoing the posterolateral approach were $62.5 \%$ higher than those among patients undergoing MIS-AL total hip arthroplasty in the first 48 hours post-operatively. Similar conclusions can be drawn from the current results in the literature [20-23], where most of the patients undergoing minimally invasive THA procedures had with lower CK levels and minor muscle damage. In our study, although pre-operative CK levels were similar in both groups, serum CK levels were lower at day 1 and day 3 after the minimally invasive transpiriformis approach and returned to normal on post-operative day three. Compared with the minimally invasive transpiriformis approach, the incision for THA with the conventional posterolateral approach was longer, averaging $15.56 \pm 1.20 \mathrm{~cm}$. In addition to bluntly splitting the gluteus maximus muscle, the traditional posterolateral approach also requires cutting the short external rotators such as the piriformis, internal obturator muscle, and gemellus superior. As a result, muscle damage is serious, and postoperative serum CK levels are high. However, $\mathrm{CK}$ levels in serum were reduced in both groups on postoperative day three, which was thought to be related to the half-life of CK. Research suggests that the increase reaches a peak 24-48 hours after muscle injury and then gradually decreases [24, 25]. Bergin et al. [20] showed that the
Table 3 Postoperative inflammation and muscle damage markers of patients

\begin{tabular}{cllll}
\hline & $\begin{array}{l}\text { Minimally invasive } \\
\text { transpiriformis approach } \\
(\mathrm{n}=49)\end{array}$ & $\begin{array}{l}\text { Posterolat- } \\
\text { eral approach } \\
(\mathrm{n}=57)\end{array}$ & Difference in means (95\%CI) & P value \\
\hline 1st post-operative day & & & \\
CRP(mg/l) & $59.51 \pm 26.28$ & $69.70 \pm 2.95$ & $3.50(-17.14-3.25)$ & 0.00 \\
IL-6(pg/ml) & $5.33 \pm 1.70$ & $6.51 \pm 1.75$ & $0.34(-1.85-0.52)$ & 0.00 \\
CK(U/L) & $476.67 \pm 87.44$ & $613.77 \pm 25.35$ & $12.13(-161.15-113.05)$ & 0.00 \\
CK-MB(U/L) & $32.42 \pm 21.85$ & $38.41 \pm 2.02$ & $2.9(-11.75--0.22)$ & 0.04 \\
MB(ng/ml) & $511.11 \pm 189.40$ & $801.09 \pm 22.47$ & $25.27(-340.10-239.87)$ & 0.00 \\
3rd postoperative day & & & \\
CRP(mg/l) & $97.21 \pm 39.27$ & $113.29 \pm 4.98$ & $5.25(-26.49-5.68)$ & 0.00 \\
IL-6(pg/ml) & $5.66 \pm 0.63$ & $6.89 \pm 4.13$ & $0.60(-2.41-0.05)$ & 0.04 \\
CK(U/L) & $370.23 \pm 249.37$ & $504.62 \pm 21.88$ & $33.15(-200.13-68.65)$ & 0.00 \\
CK-MB(U/L) & $8.28 \pm 5.86$ & $19.20 \pm 15.13$ & $2.30(-15.48-6.36)$ & 0.00 \\
MB(ng/ml) & $148.32 \pm 91.98$ & $182.14 \pm 12.51$ & $12.30(-58.22-9.42)$ & 0.01 \\
\hline
\end{tabular}




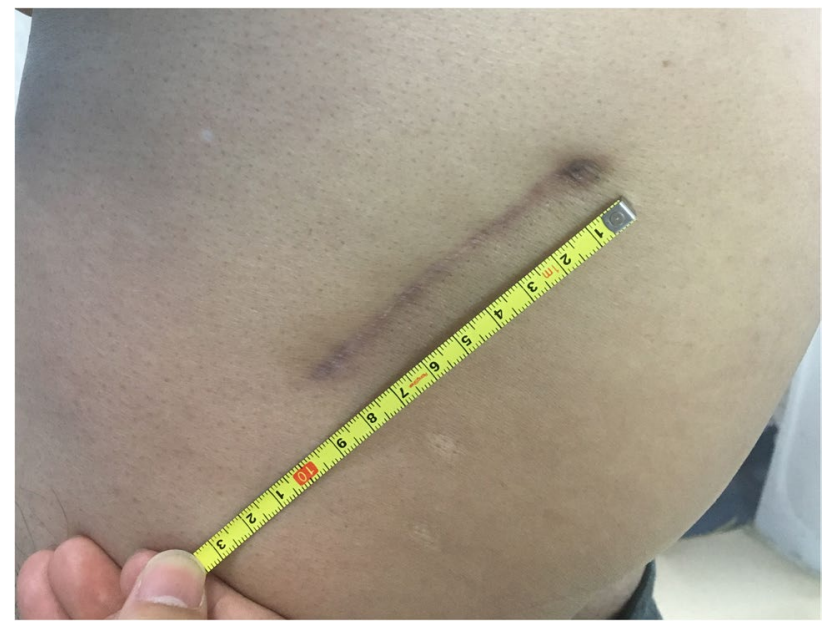

Fig. 9 The skin was closed with intradermal sutures

post-operative serum CK levels increased with increasing surgery duration, and similar results were obtained in our study. This also contributes to elevated serum CK levels after the conventional posterolateral approach. The average duration of surgery in the minimally invasive transpiriformis approach group was $84.47 \pm 19.37$ minutes, and the average time in the posterolateral approach group was $105.44 \pm 10.50$ minutes. When we analyzed the correlation between operative time and CK by Spearman's correlation analysis, we found a positive correlation between operative time and post-operative serum CK in both the minimally invasive transpiriformis group and the posterolateral group; however, the correlation was very low $(\mathrm{P}>0.05)$. This may also be related to a type 2 error due to the small number of cases in our study. Naturally, the impact may be due to several factors, such as the proficiency of the surgeon. However, our studies were all performed by the same experienced orthopedic surgeons, so the bias was small. Meanwhile, the transpiriformis surgeries were on average 20 minutes shorter than the standard posterolateral approach. The length of the surgery time is highly related to surgical proficiency. Second, the complexity of the surgical operation is also an important factor in determining the

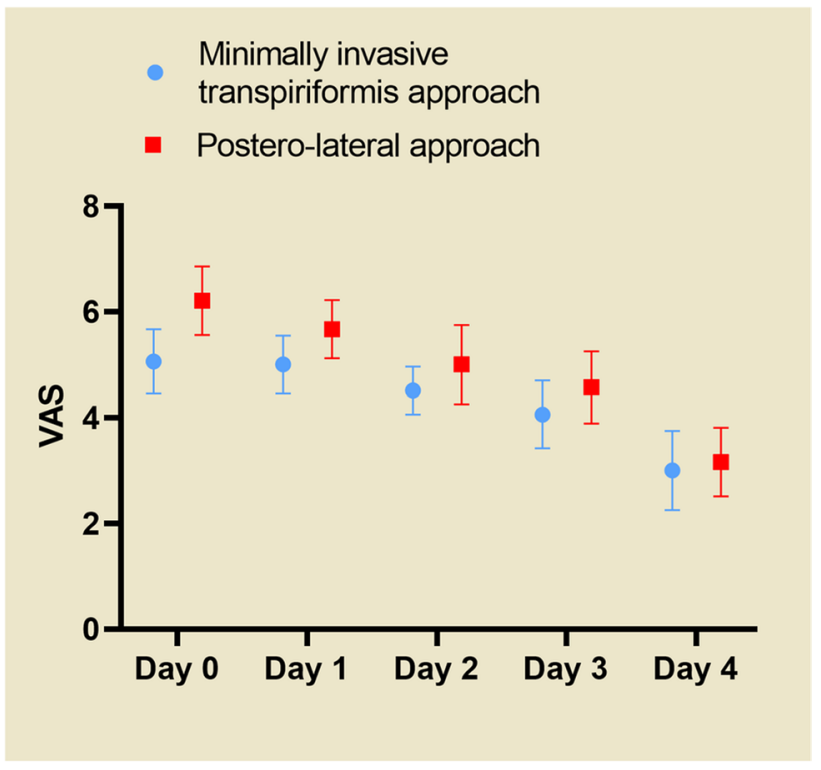

Fig. 11 The VAS of the posterolateral approach group was higher than that of the minimally invasive transpiriformis group on the third post-operative day $(\mathrm{P}<0.05)$, and the difference was statistically significant, and there was no statistically significant difference between the two groups on the fourth day of comparison $(\mathrm{P}>0.05)$

operative time. In the minimally invasive transpiriformis approach, only the joint capsule and piriformis tendon are repaired postoperatively, but in the posterolateral approach, the external rotators (internal obturator muscle and gemellus superior, respectively) is also repaired.

The body elicits a strong stress response during surgery that can cause local damage and organ dysfunction; therefore, it is important for surgeons to minimize the trauma from surgery. CRP is an acute-phase reactant and a sensitive systemic marker of inflammation and tissue injury [26]. However, under stressful conditions such as inflammation, burns, surgery, and trauma, the CRP level increases rapidly within six to eight hours after tissue injury and reaches a peak in $48 \sim 72$ hours [27, 28]. The change in serum CRP concentration is positively correlated with the degree of surgical trauma, which is a
Fig. 10 Low correlation between surgery duration and changes in CK levels regardless of whether the patients were in the minimally invasive transpiriformis group (a) or the posterolateral group (b)
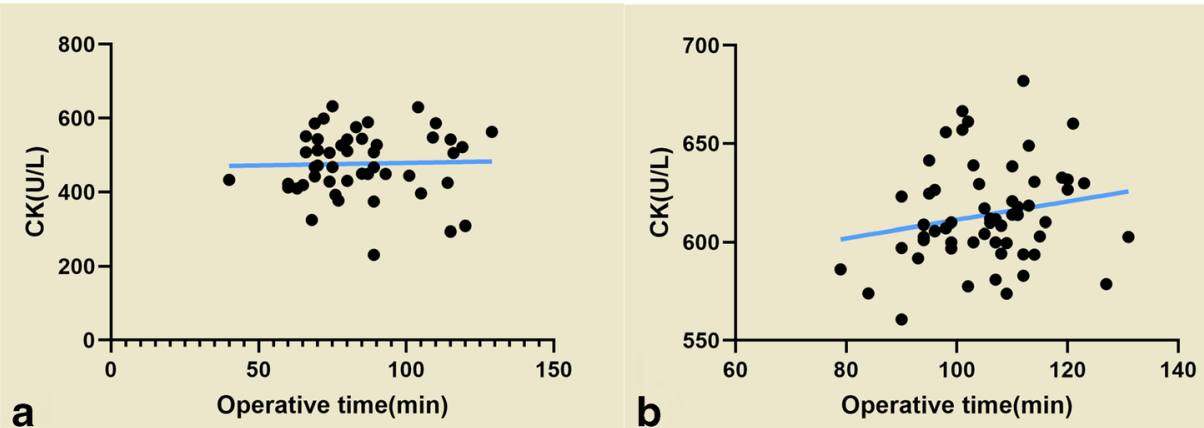
relatively sensitive indicator reflecting the degree of tissue injury[29]. In our study, post-operative CPR levels were progressively higher in both groups. Moreover, the CRP of patients in the posterolateral group was significantly more elevated than that in the minimally invasive transpiriformis group on either the first or third post-operative day $(\mathrm{P}=0.00)$. The results of one prospective study [20] and three RCTs [19, 21,23] showed low serum CRP levels in patients after minimally invasive total hip arthroplasty.

Post-operative pain is defined as acute pain associated with an inflammatory process [30], and pain is associated with inflammatory mediators [31]. Proinflammatory cytokines (TNF-a, IL-6) are released from the injury site, which in turn leads to the release of COX-2 and prostaglandin E2 (PGE2) from monocytes and macrophages. One of the causes of postoperative pain is the increased activity of the COX-2 enzyme [32]. On the one hand, COX-2 enzymes play a role in inducing inflammation by increasing the production of proinflammatory prostaglandins in arachidonic acid [33]; on the other hand, COX-2 enzymes increase pain sensitivity in peripheral tissues [34]. We found significantly lower IL-6 levels in the minimally invasive transpiriformis group postoperatively $(\mathrm{P}=0.00)$. The visual analog scale (VAS) was adopted for pain assessment in this study. Jensen et al. [35] showed that a 33\% reduction in pain was a reasonable criterion for determining whether the change in pain was meaningful from the patient's perspective. Therefore, there was no clinical difference when comparing VAS scores between the two groups on the fourth postoperative day in our study. Unfortunately, we did not monitor IL-6 levels in patient serum on the fourth post-operative day to further evaluate the relationship between VAS scores and IL-6. It is also reasonable to assume that the postoperative HSS is associated with pain and muscle damage, and although there was no difference in the VAS score between the two groups on post-operative day four, muscle damage in the posterolateral group severely affected the evaluation of the HSS. Thus, the HSS of patients in the minimally invasive transpiriformis group was significantly higher than that in the posterolateral group at one week after surgery, but this difference gradually decreased as the soft muscle tissues recovered until there was no significant difference in the HSS between the two groups at three months after surgery (Fig. 12).

Several studies have concluded that repair of the posterior joint capsule and short external rotator muscle groups is effective at preventing post-operative dislocation after THA. Relevant clinical studies have concluded that repairing these tissues compared with no repair still resulted in a higher post-operative dislocation rate of $9.5 \%$ [36, 37]. In three clinical studies $[38,39,40]$, even though the posterior capsule and short external rotators were repaired, they could not withstand the forces generated during tissue healing and failed, with a failure rate of $63-80 \%$. Figures 4 and 5 show

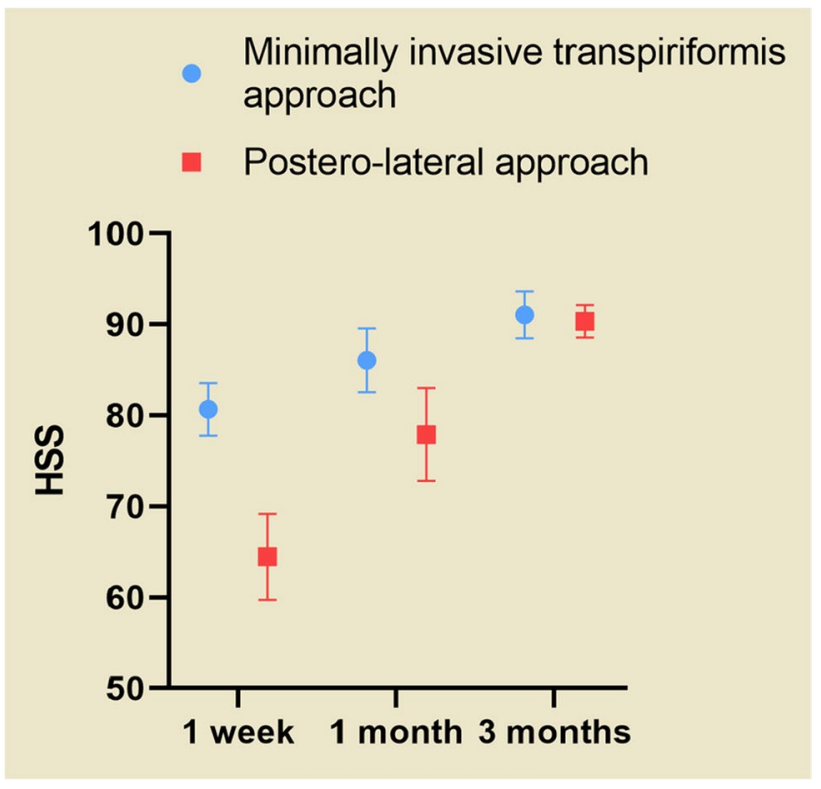

Fig. 12 The minimally invasive transpiriformis group had a higher HSS at 1 week and 1 month than the posterolateral group $(\mathrm{P}=0.00)$. The two groups had similar HSS at 3 months after surgery $(\mathrm{P}>0.05)$

that the external rotation muscle groups were well protected in our operative technique, and perhaps, the preservation of these structures may contribute to postoperative hip stability. During the six month post-operative follow-up of all our cases, only one traumatic dislocation occurred. The protection of these structures may improve post-operative gait mechanics, but further studies are needed to clarify this point.

There is still controversy about the body mass index as one of the indications for surgery, and Bostrom et al. [41] suggested that suitable candidates should be patients with a slim body type and a BMI $<30 \mathrm{~kg} / \mathrm{m} 2$, while minimally invasive surgery is not recommended for initial total hip replacement with too strong muscles and significant anatomical abnormalities. Berger et al. [42] and Roger et al. [14] believed that obesity is a relative rather than an absolute contraindication to minimally invasive surgery; they concluded that although patients with high BMI required a longer skin incision, preservation of the inferior short external was accomplished with exposure and prosthesis implantation.

Samely, we still worry about the skin incision before the surgical operation, so in the inclusion criteria, we choose patients with a slim body type and $\mathrm{BMI}<30 \mathrm{~kg} / \mathrm{m} 2$, to reduce the intra-operative strain on the surgical incision and further avoid wound problems such as skin necrosis and subcutaneous hematoma. None of the minimally invasive groups in our study had wound problems. Therefore, we believe that a lean body type with a BMI $<30 \mathrm{~kg} / \mathrm{m} 2$ remains one of the indications for minimally invasive surgery. In contrast, the procedure can still be done in patients 
with strong muscles, obesity, and BMI $>30 \mathrm{~kg} / \mathrm{m} 2$, but the intra-operative incision needs to be extended, which does not meet the definition of minimally invasive.

In conclusion, in our study, the minimally invasive transpiriformis group had minor muscle damage and a reduced inflammatory response compared to the posterolateral group. Although the minimally invasive transpiriformis approach has better clinical results in the short term, we should pay more attention to the long-term prosthesis survival rate regardless of the surgical technique used for total hip replacement. Indeed, proper placement of the prosthesis and maximum protection of the periarticular stabilization system reduces the rate of prosthetic dislocation, increases satisfaction in the short term, and contributes to long-term prosthetic survival.

Acknowledgements We thank AJE for its linguistic assistance during the preparation of this manuscript.

Funding This work was supported by the Sichuan Provincial Medical Association Special Research Fund (2020SAT46).

\section{Declarations}

Ethics approval This study is a prospective, randomized controlled trial approved by the ethics committee of the hospital.

Consent for publication Written informed consent for publication was obtained from all participants.

Conflict of interest The authors declare no competing interests.

Open Access This article is licensed under a Creative Commons Attribution 4.0 International License, which permits use, sharing, adaptation, distribution and reproduction in any medium or format, as long as you give appropriate credit to the original author(s) and the source, provide a link to the Creative Commons licence, and indicate if changes were made. The images or other third party material in this article are included in the article's Creative Commons licence, unless indicated otherwise in a credit line to the material. If material is not included in the article's Creative Commons licence and your intended use is not permitted by statutory regulation or exceeds the permitted use, you will need to obtain permission directly from the copyright holder. To view a copy of this licence, visit http://creativecommons.org/licenses/by/4.0/.

\section{References}

1. Charnley J (1964) The bonding of prostheses to bone by cement. J Bone Joint Surg Br 46:518-529

2. Pennington MW, Grieve R, van der Meulen JH (2015) Lifetime cost effectiveness of different brands of prosthesis used for total hip arthroplasty: a study using the NJR dataset. Bone Joint J 97-B:762-770

3. Ethgen O, Bruyère O, Richy F, Dardennes C, Reginster JY (2004) Health-related quality of life in total hip and total knee arthroplasty. A qualitative and systematic review of the literature. J Bone Joint Surg Am 86:963-974
4. Masonis JL, Bourne RB (2002) Surgical approach, abductor function, and total hip arthroplasty dislocation. Clin Orthop Relat Res 405:46-53

5. Brismar BH, Hallert O, Tedhamre A, Lindgren JU (2018) Early gain in pain reduction and hip function, but more complications following the direct anterior minimally invasive approach for total hip arthroplasty: a randomized trial of 100 patients with 5 years of follow up. Acta Orthop 89:484-489

6. Repantis T, Bouras T, Korovessis P (2015) Comparison of minimally invasive approach versus conventional anterolateral approach for total hip arthroplasty: a randomized controlled trial. Eur J Orthop Surg Traumatol 25:111-116

7. Higuchi F, Gotoh M, Yamaguchi N, Suzuki R, Kunou Y, Ooishi K, Nagata K (2003) Minimally invasive uncemented total hip arthroplasty through an anterolateral approach with a shorter skin incision. J Orthop Sci 8:812-817

8. Bertin KC, Röttinger H (2004) Anterolateral mini-incision hip replacement surgery: a modified Watson-Jones approach. Clin Orthop Relat Res 429:248-255

9. O'Brien DA, Rorabeck CH (2005) The mini-incision direct lateral approach in primary total hip arthroplasty. Clin Orthop Relat Res 441:99-103

10. Jacquot F, Ait Mokhtar M, Sautet A, Doursounian L, Masquelet AC, Feron JM (2013) The mini postero-postero-lateral mini incision in total hip arthroplasty. Int Orthop 37:1891-1895

11. Klasan A, Neri T, Oberkircher L, Malcherczyk D, Heyse TJ, Bliemel C (2019) Complications after direct anterior versus Watson-Jones approach in total hip arthroplasty: results from a matched pair analysis on 1408 patients. BMC Musculoskelet Disord 20:77

12. Klasan A, Oho AUID, Neri T, Oberkircher L, Malcherczyk D, Heyse TJ, Bliemel C (2019) Complications after direct anterior versus Watson-Jones approach in total hip arthroplasty: results from a matched pair analysis on 1408 patients. BMC Musculoskelet Disord 20:77

13. Penenberg BL, Bolling WS, Riley M (2008) Percutaneously assisted total hip arthroplasty (PATH): a preliminary report. J Bone Joint Surg Am 90(Suppl 4):209-220

14. Roger DJ, Hill D (2012) Minimally invasive total hip arthroplasty using a transpiriformis approach: a preliminary report. Clin Orthop Relat Res 470:2227-2234

15. Wall SJ, Mears SC (2008) Analysis of published evidence on minimally invasive total hip arthroplasty. J Arthroplasty 23:55-58

16. Suzuki K, Kawachi S, Sakai H, Nanke H, Morita S (2004) Miniincision total hip arthroplasty: a quantitative assessment of laboratory data and clinical outcomes. J Orthop Sci 9:571-575

17. Musil D, Stehlík J, Verner M (2008) A comparison of operative invasiveness in minimally invasive anterolateral hip replacement (MIS-AL) and standard hip procedure, using biochemical markers. Acta Chir Orthop Traumatol Cech 75:16-20

18. Lewinnek GE, Lewis JL, Tarr R, Compere CL, Zimmerman JR (1978) Dislocations after total hip-replacement arthroplasties. J Bone Joint Surg Am 60:217-220

19. Musil D, Stehlik J, Verner M (2008) A comparison of operative invasiveness in minimally invasive anterolateral hip replacement (MIS-AL) and standard hip procedure, using biochemical markers. Acta Chir Orthop Traumatol Cech 75:16-20

20. Bergin PF, Doppelt JD, Kephart CJ, Benke MT, Graeter JH, Holmes AS, Haleem-Smith H, Tuan RS, Unger AS (2011) Comparison of minimally invasive direct anterior versus posterior total hip arthroplasty based on inflammation and muscle damage markers. J Bone Joint Surg Am 93:1392-1398

21. Mjaaland KE, Kivle K, Svenningsen S, Pripp AH, Nordsletten L (2015) Comparison of markers for muscle damage, inflammation, and pain using minimally invasive direct anterior versus direct 
lateral approach in total hip arthroplasty: A prospective, randomized, controlled trial. J Orthop Res 33:1305-1310

22. Amanatullah DF, Masini MA, Roger DJ, Pagnano MW (2016) Greater inadvertent muscle damage in direct anterior approach when compared with the direct superior approach for total hip arthroplasty. Bone Joint J 98-B:1036-1042

23. Zhao HY, Kang PD, Xia YY, Shi XJ, Nie Y, Pei FX (2017) Comparison of early functional recovery after total hip arthroplasty using a direct anterior or posterolateral approach: a randomized controlled trial. J Arthroplasty 32:3421-3428

24 Schwane JA, Johnson SR, Vandenakker CB, Armstrong RB (1983) Delayed-onset muscular soreness and plasma CPK and LDH activities after downhill running. Med Sci Sports Exerc 15:51-56

25. Apple FS, Rhodes M (1988) Enzymatic estimation of skeletal muscle damage by analysis of changes in serum creatine kinase. J Appl Physiol (1985) 65:2598-2600

26. Kamath DY, Xavier D, Sigamani A, Pais P (2015) High sensitivity C-reactive protein (hsCRP) \& cardiovascular disease: An Indian perspective. Indian J Med Res 142:261-268

27. Hildebrand F, Pape HC, Krettek C (2005) The importance of cytokines in the posttraumatic inflammatory reaction. Unfallchirurg 108(793-794):796-803

28. Laporta Baez Y, Palomero Rodriguez MA, De Vicente Sánchez JC, Sanabria Carretero P, Al Kassam Martínez D, Pérez Ferrer A, Muriel Villoria C, Gilsanz Rodríguez F (2011) C-reactive protein in the diagnosis of postoperative infection in pediatric patients: a prospective observational study of 103 patients. J Pediatr Surg 46:1726-1731

29. Kragsbjerg P, Holmberg H, Vikerfors T (1995) Serum concentrations of interleukin-6, tumour necrosis factor-alpha, and C-reactive protein in patients undergoing major operations. Eur J Surg $161: 17-22$

30. Joel, Katz (1997). Pain begets pain: Predictors of long-term phantom limb pain and post-thoracotomy pain. Pain Forum 6:140-144

31. Ronchetti S, Migliorati G, Delfino DV (2017) Association of inflammatory mediators with pain perception. Biomed Pharmacother 96:1445-1452
32. Carreira EU, Carregaro V, Teixeira MM, Moriconi A, Aramini A, Verri WA Jr, Ferreira SH, Cunha FQ, Cunha TM (2013) Neutrophils recruited by CXCR $1 / 2$ signalling mediate post-incisional pain. Eur J Pain 17:654-663

33. Süleyman H, Demircan B, Karagöz Y (2007) Anti-inflammatory and side effects of cyclooxygenase inhibitors. Pharmacol Rep $59: 247-258$

34 Schug SA (2006) The role of COX-2 inhibitors in the treatment of postoperative pain. J Cardiovasc Pharmacol 47 Suppl 1:S82-86

35. Jensen MP, Chen C, Brugger AM (2003) Interpretation of visual analog scale ratings and change scores: a reanalysis of two clinical trials of postoperative pain. J Pain 4:407-414

36. White RE Jr, Forness TJ, Allman JK, Junick DW (2001) Effect of posterior capsular repair on early dislocation in primary total hip replacement. Clin Orthop Relat Res 163-167

37. Ko CK, Law SW, Chiu KH (2001) Enhanced soft tissue repair using locking loop stitch after posterior approach for hip hemiarthroplasty. J Arthroplasty 16:207-211

38. Stähelin T, Drittenbass L, Hersche O, Miehlke W, Munzinger U (2004) Failure of capsular enhanced short external rotator repair after total hip replacement. Clin Orthop Relat Res 199-204

39. Stähelin T, Vienne P, Hersche O (2002) Failure of reinserted short external rotator muscles after total hip arthroplasty. J Arthroplasty 17:604-607

40. Kao JT, Woolson ST (1992) Piriformis tendon repair failure after total hip replacement. Orthop Rev 21:171-174

41. Bostrom MP, Demetrakopoulos D, Reinhart J, Sculco TP (2005) Minimally invasive posterior approach to total hip replacement. Curr Opin Orthop 16:2-4

42. Berger RA, Hartzband MA (2005) Minimally Invasive Total Hip Arthroplasty: The Two-Incision Approach. Curr Opin Orthop $16: 7-31$

Publisher's note Springer Nature remains neutral with regard to jurisdictional claims in published maps and institutional affiliations. 